\title{
FAKE NEWS: DISCREPÂNCIA DE SENTIDOS E EFEITOS SOBRE AS RESISTÊNCIAS
}

\author{
Evandra Grigoletto ${ }^{\mathrm{a}}$ \\ Helson Flávio da Silva Sobrinho ${ }^{\mathrm{b}}$
}

\begin{abstract}
RESUMO
Fundamentado na Análise do Discurso pecheuxtiana, este artigo analisa, pelo viés da resistência, as discrepâncias de sentidos presentes em fake news que circularam durante a campanha eleitoral de 2018. Marcadas por equívocos e contradições, as fake news, inscritas no universo dos discursos não estabilizados logicamente, funcionam no sentido de criar obstáculos e frear as resistências do sujeito ao poder dominante.
\end{abstract}

PALAVRAS-CHAVE: discurso; fake news; resistência.

Recebido em: 13/07/19

Aprovado em: 03/10/19

\section{Primeiras palavras: os antagonismos da nossa formação social}

[...] o termo guerra ideológica apareceu recentemente ${ }^{1}$, pretendendo caracterizar as diversas operaçôes midiáticas de

a Professora e pesquisadora do Programa de Pós-Graduação em Letras da UFPE. Doutora em Teorias do Texto e do Discurso pela UFRGS (2005), e líder do Núcleo de Estudos em Práticas de Linguagem e Espaço Virtual (NEPLEV).

b Doutor em Linguística na linha de pesquisa Discurso: sujeito, história e ideologia. Professor e pesquisador da Universidade Federal de Alagoas, atuando na Graduação e na Pós-Graduação em Letras - UFAL. Bolsista Produtividade do CNPq. Vice-líder do Grupo de Estudos Discurso e Ontologia (GEDON).

1 Capitalista, e também na do "socialismo existente". 
massa desenvolvidas (em média de maneira eficaz) pela grande burguesia multinacional contra tudo o que resiste a sua política. (PÊCHEUX [1979], 2011, p. 73)

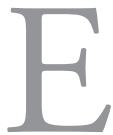

ssa citação de Pêcheux, embora remeta a outro contexto histórico, conforme explicitamos na nota do rodapé, muito nos diz sobre o momento político que vivemos, atualmente, no Brasil. A tal guerra ideológica continua reverberando mundo afora e é mais atual do que nunca, mas agora com operaçóes midiáticas muito mais modernas, com controles tecnológicos muito mais eficazes. Diríamos que, hoje, no Brasil, essa guerra ideológica remete a uma luta que vimos travando entre democracia e autoritarismo, entre Estado de direito e Estado de exceção, entre os direitos das minorias e a sua exterminaçáo, entre tantos outros antagonismos que atravessam a formaçáo social brasileira. Antagonismos esses que se inscrevem no interior da luta de classes, na luta entre burguesia e proletariado, na luta entre a ideologia dominante e as ideologias dominadas. Mas, como nos ensina Pêcheux ([1984], 2014, p. 6), é preciso entender que "a burguesia e o proletariado são formados e organizados juntos no modo de produção capitalista, sob a dominação da burguesia e, em particular, da ideologia burguesa." (grifos do autor). Logo, são próprias da luta de classes as contradiçóes, a divisão de sujeitos e sentidos. Nas palavras de Pêcheux ([1984], 2014, p. 7): “o próprio da luta ideológica de classes é se desenvolver num mundo que, de fato, não termina nunca de se dividir em dois." (grifos do autor).

Podemos dizer, então, que um dos modos de materialização desse mundo dividido, da luta ideológica de classes no Brasil, foram as candidaturas que disputaram o segundo turno da eleição presidencial de 2018: uma candidatura do campo progressista, cujo representante é o presidenciável Fernando Haddad; e outra, do campo da extrema direita, representada pelo presidenciável Jair Bolsonaro.

Agregando mais um elemento a esse cenário, trazemos outra citação desse mesmo texto de Pêcheux que também nos diz muito sobre o cenário eleitoral de 2018 no Brasil: 
Em 1940, o militar em questão, "herói de Verdun", se encontra no comando do regime de Vichy ${ }^{2}$ sob o controle alemáo, levado ao poder por uma burguesia que, entre um "inimigo" exterior, cujo regime de ordem social a fascina, e uma democracia no interior da qual as forças de esquerda encontram pontos de apoio diretos ou indiretos, não hesita um só instante: "Antes Hitler que a Frente Popular”. (PÊCHEUX [1979], 2011, p. 74)

O restante da história não é preciso narrar a nenhum leitor mais atento e conhecedor da história da Alemanha nazista. Qualquer semelhança dessa citação de Pêcheux com o cenário eleitoral brasileiro de 2018 não é mera coincidência. Entre os enunciados que mais circularam e são repetidos insistentemente pelos eleitores de Bolsonaro estão "PT NÃO; PT nunca mais; qualquer um, menos o PT; corrupPTos não passarão", os quais podem deslizar, parafrasticamente, para "Antes Bolsonaro que o PT". Assim, como no caso do regime nazista, trata-se de disseminar o ódio, não exatamente contra um candidato, mas contra um partido e o que ele representa. Podemos dizer, nesse caso, que estamos diante de uma luta que está alinhada aos interesses dominantes, à máquina do capital, representada sobretudo pela ideologia burguesa, que não quer que um Partido progressista assuma, mais uma vez, o poder, pois permitiria às classes proletárias, às ideologias dominadas, representadas sobretudo pelos cidadãos mais pobres e as minorias desse País, alguns direitos a mais, algum protagonismo e dignidade. Paradoxalmente, apaga-se, nesse discurso, o fato de que os governos do PT também beneficiaram os grandes empresários, governaram de modo a elevar todos os índices econômicos e de que a corrupção está longe de ser uma exclusividade do Partido dos Trabalhadores

2 Pêcheux refere-se aqui a Phillipe Pétain, um militar francês, que atuou como chefe de estado da França de Vichy, de 1940 a 1944. Durante a Segunda Guerra Mundial, com a queda iminente da França em junho de 1940, Pétain foi nomeado primeiro-ministro da França pelo presidente Lebrun em Bordeaux, e o gabinete resolveu fazer a paz com a Alemanha. $\mathrm{O}$ governo inteiro, posteriormente, se moveu brevemente para Clermont-Ferrand, depois para a cidade termal de Vichy, no centro da França. Seu governo votou em transformar a desacreditada República Francesa no Estado francês, um regime autoritário alinhado com a Alemanha nazista (Informações disponíveis em: https://pt.wikipedia.org/wiki/Philippe_P\%C3\%A9tain. Acesso em 27 out. 2018). 
no Brasil, porque é algo intrínseco ao funcionamento do sistema capitalista.

Partindo desse cenário, interessa-nos olhar, mais especificamente, o funcionamento discursivo das fake news nas eleiçóes presidenciais de 2018, observando como elas podem atuar para frear os movimentos de resistência nas práticas das ideologias dominadas, aqueles que se inscrevem no campo progressista, buscando transformaçóes sociais. Em outras palavras, nossa proposta tem o objetivo de analisar os efeitos dessa discursividade que se impóe nas mídias sociais produzindo equívocos e fortalecendo, em seu modo de circulação, os interesses dominantes capazes de frear as resistências e as possibilidades de transformaçóes. Trata-se de discursividades prêt-à-porter, conforme entendimento de Mariani (2018, p. 6-7), as quais "têm sua eficácia ao colocar em circulação determinados sentidos que podem produzir aderência, ou seja, um colamento a determinados sentidos já sob o efeito de evidência.".

Pêcheux ([1979], 2011) ao falar sobre a história de luta, dos séculos XIX e XX, entre duas vias do capitalismo, que ele simplifica em linha parlamentarista (via 1) e linha militar (via 2), alerta-nos para o seguinte:

E é nesse duplo espaço que se formaram concretamente as condiçôes de exercício das propagandas políticas, através de uma longa série de tentativas de emprestar, tomar a palavra, desviar, virar, desnaturar as bases práticas do adversário de classe, segundo um princípio que não parou de ecoar historicamente entre a burguesa e o proletariado e que se enuncia assim: "Se isso funciona tão bem para eles, por que não funcionaria para nós?” ” (PÊCHEUX [1979], 2011, p. 82, grifos do autor)

Esse jogo de palavras, determinado pelo ideológico, do qual Pêcheux nos fala e que são as condiçóes de exercício das propagandas políticas, continua funcionando muito bem e atravessando a disputa eleitoral nos dias atuais. No entanto, trazendo isso para o contexto da eleição presidencial brasileira de 2018, é preciso que estejamos atentos ao que representa esse jogo em cada um dos lados: o que funciona para eles, não funciona necessariamente para nós, como sugere a questão que fecha a citação. Do lado deles, a posição ideológica 
sustentada, sob uma fachada democrática, é racista, homofóbica, autoritária, intolerante, misógina, defende o armamento da população, e ameaça "banir" todos aqueles que representarem oposição ao seu governo, como o próprio candidato, Jair Bolsonaro, anunciou no domingo, 20 de outubro de 2018: "Esses marginais vermelhos serão banidos de nossa pátria". E acrescentou: "Será uma limpeza nunca vista no Brasil"”. Os "marginais vermelhos" a que ele se refere são os eleitores de Fernando Haddad, que, representando o lado de cá dessa eleição, tomam posição, sobretudo, pela manutenção da democracia, mas também pelo respeito à diversidade, pela autonomia das instituiçóes e por um Brasil mais justo e menos desigual.

Portanto, nesse jogo entre o eles (tidos como "cidadãos de bem") e os outros (tidos como "marginais vermelhos"), no qual o jogo de palavras, no funcionamento do discurso, tem um papel fundamental, a campanha de Jair Bolsonaro aproveitou-se da eficácia, do efeito de evidência dessa discursividade prêt-à-porter, que resulta em um "novo" tipo de propaganda: a produção em massa de fake news, que circulam sobretudo nas redes sociais. Podemos dizer que essa eficácia, como nos mostra Pêcheux (2011, p. 84), vira "ao contrário as práticas do movimento operário" [...], "tirando partido das contradiçôes veiculadas por essas práticas.”. No caso da eleição presidencial brasileira, não se tratou necessariamente de virar ao contrário as práticas do movimento operário, mas de distorcer, manipular informaçóes sobre os candidatos Fernando Haddad e sua vice, Manuela D'Ávila, produzir mentiras sobre programas implementados nos governos petistas. Estamos entendendo, nesse sentido, que as fake news funcionam como uma arma para frear, "anestesiar as resistências" (PÊCHEUX, 2011, p. 92) do campo progressista, das frentes de esquerda, que lutam por uma eleição, de fato, democrática. Analisaremos, a seguir, alguns exemplos dessas fake news e o modo como elas funcionam discursivamente.

3 Como afirma a jornalista Eliane Brum, no seu artigo de opinião, publicado no jornal El País, em 24 de outubro de 2018: "No governo autoritário anunciado por Bolsonaro, quem tem o poder e terá o aparato de repressão na mão pode dizer o que somos eu e você.” Disponível em: https://brasil.elpais.com/brasil/2018/10/24/opinion/1540394956_656180.html. Acesso em 27 out. 2018. 


\section{Ainda as palavras: o fenômeno das fake news em análise}

Antes de analisarmos os exemplos que selecionamos para este trabalho, é preciso dizer que essa foi uma eleição marcada por esse fenômeno das fake news, que não é um fenômeno novo, mas que se potencializou e se multiplicou, sobretudo nas redes sociais, nessa eleição de 2018 no Brasil. No entanto, conforme nos afirmam Adorno e Silveira (2017, p. 3), embora exista

uma generalização de que vivemos a era da Fake News por causa da internet, o que permite a muitos afirmar que a internet é a grande produtora de Fake News, ou, que são os sujeitos usuários das mídias sociais digitais os responsáveis pelas Fake News [...], é também com a internet que surgem os sites e mecanismos que permitem checar a "veracidade" dos fatos e notícias que circulam não só na internet, mas em outros meios ou veículos de informação.

Os autores nos sugerem que as fake news não surgiram, necessariamente, com a internet, pontuando que se, por um lado, ela tem potencializado a sua disseminação, por outro, tem sido fundamental também para a checagem do que é fato e do que é fake.

O que se pôde apurar, e foi divulgado pela imprensa sobre esse fenômeno, é que houve mais de uma centena de notícias falsas que circularam, sobretudo nas redes sociais, envolvendo os candidatos à Presidência da República $^{4}$, e dessas a esmagadora maioria era contra a candidatura do presidenciável Fernando Haddad e o seu partido. Tais dados reforçam nossa hipótese de que as fake news funcionaram, nesse caso, para frear as resistências do campo progressista, que apoiam o candidato petista.

4 Encontramos em vários sites a manchete de que um levantamento feito, pelas principais agências de checagem, comprova que das " 123 fakenews encontradas por agências de checagem, 104 beneficiaram Bolsonaro” (Notícia disponível em: https://congressoemfoco.uol. com.br/eleicoes/das-123-fake-news-encontradas-por-agencias-de-checagem-104-beneficiaram-bolsonaro/). 
Julgamos importante também mencionar a reportagem, publicada no Jornal Folha de São Paulo (FSP), assinada pela jornalista Patrícia Campos Mello, no dia 18 de outubro de 2018, cujo título - "Empresários bancam campanha contra o PT pelo WhatsApp" $5_{7}$ - sugeria prática ilegal da campanha de Bolsonaro. Após a publicação dessa reportagem, o PT e outros partidos abriram processo no Tribunal Superior Eleitoral solicitando, entre outras coisas, investigação de possível caixa 2. Tal reportagem teve muitos outros desdobramentos na campanha, como várias ameaças e xingamentos sofridos pela repórter da Folha responsável pela matéria, vindas dos apoiadores de Jair Bolsonaro ${ }^{6}$, inclusive de um dos filhos deles, o deputado Eduardo Bolsonaro $^{7}$, que a ameaçou de morte, como podemos ver no diálogo que aqui reproduzimos:

EDUARDO BOLSONARO: "Sua otária! Quem você pensa que é? Tá se achando demais. Se você falar mais alguma coisa eu acabo com sua vida"

PATRICIA: "Isso é uma ameaça???”

EDUARDO BOLSONARO: "Entenda como quiser. Depois reclama que apanhou. Você merece mesmo. Abusada. Tinha que ter apanhado mais pra aprender a ficar calada. Mais uma palavra e eu acabo com você. Acabo mais ainda com a sua vida"

PATRICIA: "Eu estou gravando"

EDUARDO BOLSONARO: "Foda-se. Ninguém vai acreditar em você. Nunca acreditaram. Somos fortes"

5 Disponível em: Acesso em: https://www1.folha.uol.com.br/poder/2018/10/empresarios -bancam-campanha-contra-o-pt-pelo-whatsapp.shtml. Acesso em: 23 out. 2019.

6 Informações disponível em: https://www.revistaforum.com.br/jornalista-que-fez-materiade-denuncia-contra-bolsonaro-e-alvo-de-ataques-nas-redes/. Acesso em: 28 out. 2018.

7 Informação disponível em: https://www.gazetadopovo.com.br/blogs/caixa-zero/bolsonarofilho-e-apoiadores-fazem-ameacas-a-jornais-e-reporteres/. Acesso em: 28 out. 2018. 
PATRICIA: "Me aguarde pois vou falar"

EDUARDO BOLSONARO: "Vai para o inferno. Puta. Você vai se arrepender de ter nascido. $\mathrm{O}$ aviso está dado. Mais uma palavra e eu vou pessoalmente atrás de você. Não pode me envergonhar.

PATRICIA: "Tchau"

EDUARDO BOLSONARO: "Vagabunda"

PATRICIA: "Resolvemos na justiça. É a melhor forma"

EDUARDO BOLSONARO: "Enfia a justiça no cú””

Embora não seja esse o foco da nossa análise, é interessante observar, nesse diálogo, como a campanha do candidato se coloca acima de qualquer instituição, acima da justiça e de órgãos tradicionais da imprensa brasileira. Curioso, ainda, que, ao ameaçar explicitamente a jornalista de morte, reconhece que há coisas que não podem/devem vir a público: "Mais uma palavra e eu acabo com você. Acabo mais ainda com a sua vida.". Colocamse, assim, como se fossem os donos da "verdade", tentando calar qualquer tipo de resistência ao "projeto" que eles representam para o País, como já destacamos ${ }^{8}$.

Ainda nessa esteira de calar as resistências, Jair Bolsonaro afirmou, em vídeo produzido aos seus apoiadores no domingo, 20 de outubro de 2018, que a "Folha é a maior fake news do Brasil"". Na tentativa de inverter o efeito produzido pela divulgação da reportagem, o candidato e seus apoiadores acusam a Folha de São Paulo (FSP) de produzir uma fake news, estra-

8 O efeito de "verdade" também se produziu no discurso do candidato Bolsonaro a partir das reiteradas citaçóes do versículo bíblico, João 8:32 "E conhecereis a verdade, e a verdade vos libertará”.

9 Disponível em: https://www1.folha.uol.com.br/poder/2018/10/folha-e-a-maior-fake-newsdo-brasil-diz-bolsonaro-a-manifestantes.shtml. Acesso em: 28 out. 2018. 
nhamente a arma de que a sua campanha tanto se utilizou. "Cego a suas contradiçôes" (PÊCHEUX [1979], 2011, p. 85), o candidato tenta tirar partido de tudo aquilo que o liga à corrupção, à intolerância, ao fascismo etc, na tentativa de acelerar, mais uma vez, o fim das resistências. Por fim, também queremos registrar que, após a denúncia feita pela FSP, o facebook retirou do ar 68 páginas e 43 contas vinculadas à campanha de Bolsonaro ${ }^{10}$, que disseminavam conteúdos falsos, colocando em xeque o efeito de evidência da verdade.

Apresentar um pouco desse emaranhado de discursos que se entrecruzam, com as contradiçóes que lhes são inerentes, nessa fábrica de fake news, teve como objetivo situar o leitor sobre as condiçóes de produção em que essas discursividades prêt-à-porter ${ }^{10}$ se produziram e circularam durante a campanha presidencial de 2018. Tal tipo de propaganda política - se assim podemos chamá-la - tem no seu cerne uma estratégia discursiva "obstinada a evacuar qualquer contradição e a mascarar a existência das relaçóes de classes: ela usa uma falsa aparência para contornar indefinidamente o que todo mundo sabe e que ninguém pode dizer." (PÊCHEUX [1979], 2011, p. 86). A falha retorna, assim, "pelo viés do absurdo" (PÊCHEUX [1979], 2011, p. 87), para fazer parecer verdade aquilo que é da ordem do absurdo, produzindo um efeito ideológico desestruturador. Entendemos que as fake news são produzidas nessa ordem do absurdo mesmo. No caso em análise, não produzindo furo na ideologia dominante, na qual elas se inscrevem, mas no interior das próprias resistências, como uma forma de barrá-las, tentando produzir um efeito de verdade para aquilo que é absurdo. Para observar as discrepâncias de sentido que funcionam nesses discursos fakes, selecionamos, para análise duas dessas "notícias". Vejamos:

10 Estamos considerando aqui como discursividades prêt-à-porter àquelas que estão prontas para o consumo, conforme definição de Mariani (2018). 
Ao completar 5 anos de idade, a criança passa a ser propriedade do Estado! Cabe a nós decidir se menino será menina e viceversa! Aos pais cabe acatar nossa decisão respeitosamente! Sabemos o
que é melhor para as crianças!

Fernando Haddad

Figura 1: Fake news sobre suposta declaração de Haddad que circulou nas redes sociais. ${ }^{11}$

Nesse primeiro caso, circulou nas redes sociais essa montagem, produzida facilmente por qualquer internauta, com uma foto de Haddad e a suposta declaração do presidenciável: "Ao completar 5 anos de idade, a criança passa a ser propriedade do Estado! Cabe a nós decidir se menino será menina e vice-versa! Aos pais cabe acatar nossa decisão respeitosamente! Sabemos o que é melhor para as crianças!"

Tal declaração, atribuída ao presidenciável Fernando Haddad, foi considerada falsa e vetada pelo Tribunal Superior Eleitoral (TSE), em 25 de setembro de 2018. Mesmo assim, segundo reportagem de Clara Becker, ela seguia "viva" nas redes sociais ${ }^{12}$. Antes de ser vetada, a postagem tinha quase $150 \mathrm{mil}$ compartilhamentos e, mesmo depois da proibição pelo TSE, os compartilhamentos já chegavam a 10 mil, produzindo, assim, o efeito de verdade desejado. Como afirma Mariani (2018, p. 7), o que está em jogo, no compartilhamento dessas discursividades, é o interesse dos grupos políticos hegemônicos,

11 Imagem disponível em: https://aosfatos.org/media/cke_uploads/2018/09/24/haddadfake1. jpg, a partir da notícia publicada no site Aos Fatos. Acesso em: 23 out. 2019. Autoria desconhecida, já que se trata de uma notícia falsa.

12 Disponível em: https://piaui.folha.uol.com.br/lupa/2018/09/27/verificamos-haddad-criancas/. Acesso em: 10 jul. 2019. 
que tentam impor um sentido único aos fatos. Assim, "o discurso político de marketing a serviço de instâncias de poder constrói ficções a partir de acontecimentos, coloca essas ficções em circulação e as alimenta continuamente, [...] visando uma aderência à discursividade prêt-à-porter e um efeito-cola, de adesão, com novos reenvios.”.

Vejamos a segunda materialidade discursiva:
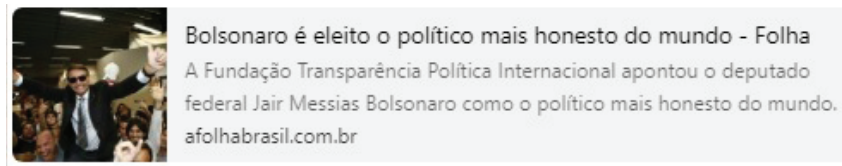

\begin{abstract}
A Fundação Transparência Política Internacional apontou o deputado federal Jair Messias Bolsonaro como o político mais honesto do mundo. Barack Obama está em segundo lugar o presidente da França François Hollande.

\section{http://afolhabrasil.com.br/uncategorized/bolsonaro-e-eleito-o-politico-mais-} honesto-do-mundo

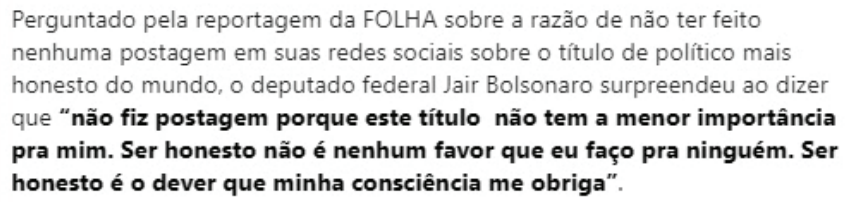

Figura 2: Fake news sobre suposta eleição de Bolsonaro como o político mais honesto do mundo13 15

Nessa materialidade discursiva, compartilha-se uma "notícia” que veicula como conteúdo a eleição, pela Fundação Transparência Política Internacional, de Jair Bolsonaro como o político mais honesto do mundo. Ocorre que tal fundação não existe, tampouco o ranking mundial de políticos honestos. E, caso tal ranking existisse, caberia a pergunta: estaria Bolsonaro nele? Deixamos ao leitor a reflexão sobre uma possível resposta. Tal notícia falsa, publicada

13 Imagem disponível em: https://aosfatos.org/media/cke_uploads/2018/10/15/bolsonarotransparencia.jpg, a partir da notícia publicada no site Aos Fatos. Acesso em: 23 out. 2019. Autoria desconhecida, já que se trata de uma notícia falsa, mas que circulou amplamente nas redes sociais na campanha de 2018. 
pelo Folha do Brasil, circulava nas redes sociais desde 2016, chegando a ocupar o topo das pesquisas (político mais honesto do mundo) no buscador do Google entre 2016 e $2017^{14}$. Mesmo que inverídica, essa notícia produziu um efeito de verdade pela repetibilidade, isto é, o grande número de compartilhamentos acabou por provocar nos sujeitos uma adesão àquilo que queriam acreditar. No jogo dos sentidos, observamos como funcionam os efeitos de discrepância: é pelo viés das relações imaginárias (político honesto versus político corrupto) que os eleitores podem identificar-se com um "denominado" político ideal que não se deixa corromper. Nessas mesmas relaçóes de sentidos discrepantes, há um reforço na interpretação que vigorou nas eleiçóes de que o PT é o partido mais corrupto do mundo.

Como podemos ver nessas materialidades discursivas, os efeitos da ideologia dominante atuam de modo diferenciado, mas tendem a produzir as mesmas consequências políticas de frear a crítica e a resistência, ou seja, reproduzir a dominação sobre os sujeitos, pois essa discursividade afeta de maneira cruel e enganadora as subjetividades. Cabe observar que esses discursos, em seu funcionamento e em seus efeitos de sentidos que circulam nas mídias sociais, nem sempre são chamados de fake news ou reconhecidos como tais; em sua maioria, são vistos em seu caráter "informativo", como se fossem tipos de mensagens que querem "alertar" o leitor "desavisado". As materialidades, por exemplo, "criança passa a ser propriedade do Estado! Cabe a nós decidir se menino será menina e vice-versa", ou ainda, "Bolsonaro foi eleito o político mais honesto do mundo", fazem "crer" que esses dizeres são naturalmente "dados". Não há questionamento sobre o locutor ou sobre o lugar de onde se está falando. Não se questionam as posiçôes sujeitos. Muitas vezes, nessa leitura de mundo, há cumplicidade entre o locutor e o interlocutor. Nesse funcionamento, muitos sujeitos, por sua vez, tomam a informação "como se fosse uma verdade", e esse efeito fake, efeito de verdade que diz o falso, orienta as açóes e as práticas dos sujeitos para posiçôes conservadoras e, até mesmo, ultraconservadoras (fascistas).

14 Tal informação pode ser confirmada na reportagem de Ana Rita Cunha, disponível em: https://aosfatos.org/noticias/bolsonaro-nao-foi-eleito-o-politico-mais-honesto-do-mundo/. Acesso em: 23 out. 2019. 
Cabe destacar também que os efeitos são controversos: quando se refere ao Haddad, produz-se ojeriza, raiva, ódio, e isso impede de o interlocutor buscar a verificação da notícia, questionar a evidência. Quando se refere ao Bolsonaro, o fake produz, para o leitor identificado (ou ainda indeciso em seu voto) com o candidato, o efeito de admiração, certeza e acerto, fazendo crer em sua "honestidade", passando a considerá-lo um "mito"15.

As duas materialidades discursivas (discursividades prêt-à-porter) analisadas nos chamam atenção por seu funcionamento político-ideológico, pois tendem a atuar no impedimento de práticas políticas que atendam às necessidades da classe trabalhadora. Estamos dizendo isso, pois não se pode perder de vista a relação do discurso com suas condições materiais e ideológicas na sociedade capitalista. As fake news que circularam nas eleiçóes de 2018 polarizaram "direita" e "esquerda", em um jogo discursivo marcado por efeitos discrepantes de "verdades" e "mentiras", determinadas pelas posições sujeito dominadas pelos interesses do capital, enquanto base histórica dessas contradiçôes discursivas e raciocínios antagonistas. Assim, produziram mais que fumaça nas eleições; reproduziram também ilusôes de que os sujeitos, tanto de um lado como do outro, estavam efetivamente fazendo "livres" "escolhas" e "redirecionando" a política e a economia do país.

Quando levamos isso em consideração, podemos compreender também a eficácia do funcionamento da ideologia burguesa, pois, sob o comando do capital, foram formulados discursos da ordem do absurdo que, por um lado, diziam que Haddad, no poder de Estado, iria tomar as crianças como "propriedades", "decidir" seu sexo e gênero, e, aos pais, caberia apenas "acatar respeitosamente". E, por outro, diziam que o nome do candidato Bolsonaro foi escolhido como "o político mais honesto do mundo", numa tentativa de interpelar o eleitor: "Vamos divulgar, quem sabe o Brasil acorda e coloca um político exemplar para comandar o Brasil”. Assim, os interesses ideológicos foram colocados em jogo, e essas notícias fake criaram obstáculos para qualquer discordância, pois funcionam como argumento de autoridade em seu efeito de "verdade". A nosso ver, os efeitos ideológicos das fake news assustam, pois

15 Jair Bolsonaro, durante a campanha eleitoral, foi chamada do "Mito", imagem que ainda permanece e foi reforçada, entre alguns de seus fiéis seguidores, após sua eleição. 
fazem crer em "mentiras", tomadas como "verdades" em seus efeitos de evidência de sentidos, ainda que sejam efeitos produzidos pelo absurdo. Ou seja, contraditoriamente, "comunicam e não comunicam", e seus efeitos materiais na história contribuem para a reprodução das relaçóes capitalistas.

Diante do que dissemos, é preciso inscrever-se do ponto de vista da resistência e voltar a Pêcheux ([1978], 1988, p. 304) para reafirmar que há sempre resistência e que "é preciso ousar se revoltar" e "ousar pensar por si mesmo". Nessa perspectiva, compreendemos que nossa prática de resistência precisa também revelar, pela análise dos efeitos das fake news, os limites da "democracia" burguesa, seus vícios, suas manobras, seus jogos, suas estratégias que visam a não ceder espaço, nem político nem econômico, à classe trabalhadora. Portanto, é preciso ousar se revoltar nesse processo histórico de produção e confrontação de sentidos e sujeitos e, sobretudo, não adotar as mesmas estratégias, pois o que serve para eles náo servem para nós.

\section{Palavras finais: as fake news continuam produzindo efeitos...}

Em nosso estudo, compreendemos a necessidade e urgência de analisar, com rigor crítico, as fake news e suas discrepâncias de sentidos do ponto de vista da resistência. Arcamos com o desafio de desenvolver uma reflexão que encara o discurso da ideologia dominante, em suas relaçóes contraditórias, para confrontar seus sentidos, desmascarar as posiçóes sujeitos. Por isso, inscrevemo-nos na dialética da história, dessa nossa história marcada por conflitos impiedosos. Portanto, produzir resistência é, para nós, não só um desafio, mas um compromisso de responsabilidade ética e política, como diria Pêcheux (2002, p. 57). Nessa perspectiva, as fake news devem ser criticadas, e este gesto teórico e político do analista de discurso (gesto que implica pensar como esses universos discursivos logicamente instáveis, marcados por ambiguidades, deslizes de sentidos e equívocos são capazes de política) pode fazer-nos lutar contra os discursos que criam obstáculos, que buscam "aniquilar" às resistências e "banir" os sujeitos ardentes. 


\section{Referências}

ADORNO, Guilherme; SILVEIRA, Juliana da. Pós-verdade e fake news: equívocos do político na materialidade digital. In: Anais do Sead. Recife, 2017, p. 1-6. Disponível em: http://www.anaisdosead.com.br/8SEAD/SIMPOSIOS/ SIMPOSIO\%20V_GAdorno\%20e\%20JSilveira.pdf. Acesso em: 10 jul. 2019.

ARAGÃO, Alexandre. Haddad nunca disse que cabe ao Estado decidir sexualidade de crianças. Aos fatos. https://aosfatos.org/noticias/haddad-nunca-disse-que-cabe-ao-estado-decidir-sexualidade-de-criancas/, 23/10/2019.

BECKER, Clara. \#Verificamos: Vetada pelo TSE, declaração falsa atribuída a Haddad segue viva nas redes sociais. Lupa. https://piaui.folha.uol.com.br/ lupa/2018/09/27/verificamos-haddad-criancas/, 23/10/2019.

BRUM, Eliane. Aos indecisos, aos que se anulam, aos que preferem não: o maior delírio hoje vivido no Brasil é o da "normalidade". El Pais. https:// brasil.elpais.com/brasil/2018/10/24/opinion/1540394956_656180.html, 27/10/2018.

CUNHA, Ana Rita. Bolsonaro não foi eleito o político mais honesto do mundo. Aos fatos. https://aosfatos.org/noticias/bolsonaro-nao-foi-eleito-o-politico-mais-honesto-do-mundo/, 23/10/2019.

FÓRUM. Jornalista que fez matéria de denúncia contra Bolsonaro é alvo de ataques nas redes. Revista fórum. https://revistaforum.com.br/politica/jornalista-que-fez-materia-de-denuncia-contra-bolsonaro-e-alvo-de-ataques-nas-redes/, 23/10/2019.

GALINDO, Rogério. Bolsonaro, filho e apoiadores fazem ameaças a jornais e repórteres. Gazeta do povo. https://www.gazetadopovo.com.br/vozes/caixa-zero/bolsonaro-filho-e-apoiadores-fazem-ameacas-a-jornais-e-reporteres/, 23/10/2019.

MACEDO, Isabella. Das 123 fake news encontradas por agências de checagem, 104 beneficiaram Bolsonaro. Congresso em foco. https://congressoemfoco.uol.com.br/eleicoes/das-123-fake-news-encontradas-por-agencias-de-checagem-104-beneficiaram-bolsonaro/, 23/10/2018.

MARIANI, Bethania. Discursividades prêt-à-porter, funcionamento de fake news e processos de identificação. Entremeios: revista de estudos do discurso. Vol. 17: 3-18, Pouso Alegre, jul. - dez. 2018. Disponível em: http://dx.doi. org/10.20337/ISSN2179-3514revistaENTREMEIOSvol17pagina3a18. 
MARQUES, José. Folha é a maior fake News do Brasil, diz Bolsonaro a manifestantes. Folha de São Paulo. https://www1.folha.uol.com.br/poder/2018/10/ folha-e-a-maior-fake-news-do-brasil-diz-bolsonaro-a-manifestantes.shtml, 23/10/2019.

MELLO, Patrícia Campos. Empresários bancam campanha contra o PT pelo WhatsApp. Folha de São Paulo. https://wwwl.folha.uol.com. br/poder/2018/10/empresarios-bancam-campanha-contra-o-pt-pelo -whatsapp.shtml, 23/10/2019.

PÊCHEUX, Michel. Foi "propaganda" mesmo que você disse? In: - Análise de discurso: Michel Pêcheux. Textos selecionados por Eni Puccinelli Orlandi. 2a ed., Campinas, SP: Pontes Editores, 2011[1979]. p. 73 - 92.

. Ousar pensar e ousar se revoltar. Ideologia, marxismo, luta de classes. Décalages. Vol 1: Issue 4, p. 1-22, 2014 [1984]. Disponível em: https://scholar.oxy.edu/decalages/vol1/iss4/15/

. $O$ discurso: estrutura ou acontecimento. $3^{\text {a }}$ Ed. Campinas, SP: Pontes, 2002 [1983].

. [1978]. Só há causa daquilo que falha ou o inverno político francês: início de uma retificação. In: Semântica e Discurso. Campinas: Editora da Unicamp, 1988 [1978]. p. 293 - 304.

TOLEDO, Luiz Fernando. Maior rede pró-Bolsonaro do facebook é excluída após denúncia do 'Estado'. O Estado de São Paulo. https://politica.estadao.com.br/noticias/eleicoes, maior-rede-pro-bolsonaro-dofacebook=-e-excluida-apos-denuncia-do-estado70002558430,?fromwhatsapp, 23/10/2019.

WIKIPÉDIA. Phillipe Pétain. Wikipédia. https://pt.wikipedia.org/wiki/ Philippe_P\%C3\%A9tain, 23/10/2019. 


\title{
FAKE NEWS: DISCREPANCY OF SENSES AND EFFECTS ON RESISTANCE
}

\author{
ABSTRACT \\ Based on Discourse Analysis from the perspective of \\ Michel Pêcheux, this article analyzes, by resistance \\ bias, this article analyzes the meaning discrepancies \\ present in fake news that circulated during the 2018 \\ election campaign. Marked by misunderstandings and \\ contradictions, fake news, inscribed in the universe of \\ discourses not stabilized logically, function to create \\ obstacles and to restrain the resistances of the subject to \\ the dominant power.
}

KEYWORDS: discourse; fake news; resistance. 
